
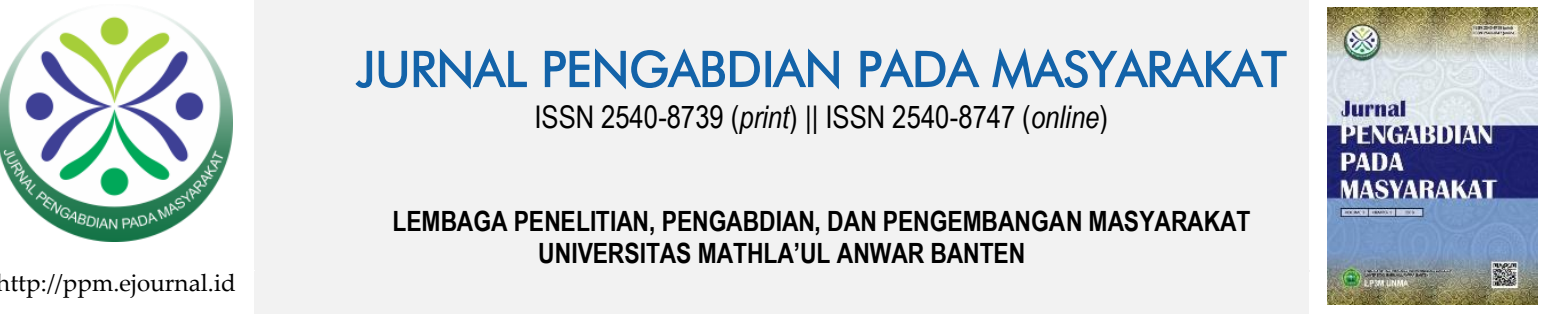

\title{
Pemberdayaan Masyarakat Untuk Menciptakan Desa Ekowisata di Wonosalam, Kabupaten Jombang
}

\author{
Dewa Gde Satrya ${ }^{1}$, Thomas Stefanus Kaihatu², Lexi Pranata ${ }^{3}$ \\ 1, 2,3 Universitas Ciputra Surabaya
}

\begin{tabular}{|c|c|}
\hline ARTICLE INFO & ABSTRACT \\
\hline \multirow{8}{*}{$\begin{array}{l}\text { Article History: } \\
\text { Received 23.08.2018 } \\
\text { Received in revised } \\
\text { form } 23.10 .2018 \\
\text { Accepted } 30.11 .2018 \\
\text { Available online } \\
21.12 .2018\end{array}$} & Ecotourism in Wonosalam, precisely in the hamlet of Mendiro, Panglungan \\
\hline & Village, which was developed through community service grants has the \\
\hline & opportunity to be collaborated with agrotourism. Agro tourism consists of 5 \\
\hline & tourist attractions: botanical gardens, plantations, food crops and \\
\hline & horticulture, fisheries and livestock. This report is based on community \\
\hline & service activities with the theme of creating an ecotourism village, in which \\
\hline & $\begin{array}{l}\text { the process has the opportunity to be integrated and strengthened by } \\
\text { agrotourism destinations. In conclusion, Wonosalam can be developed into } \\
\text { an ecotourism village destination and an agrotourism village. }\end{array}$ \\
\hline & Keywords: Agrotourism, Ecotourism. \\
\hline
\end{tabular}

DOI: $10.30653 / 002.201832 .57$

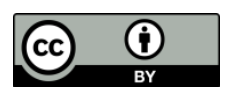

This is an open access article distributed under the terms of the Creative Commons Attribution 4.0 International License, which permits unrestricted use, distribution, and reproduction in any medium, provided the original work is properly cited. @ 2018 Dewa Gde Satrya, Thomas Stefanus Kaihatu, Lexi Pranata.

\section{PENDAHULUAN}

Ekowisata memiliki bagian yang tidak terpisahkan dengan upaya-upaya konservasi, pemberdayaan ekonomi lokal dan mendorong respek yang lebih tinggi terhadap perbedaan kultur atau budaya (Fandeli, 2000; Damanik \& Weber, 2006; Satria, 2009: 37). Hal inilah yang mendasari perbedaan antara konsep ekowisata dengan model wisata konvensional. Secara sederhana, konsep ekowisata menghubungkan antara perjalanan wisata alam yang memiliki visi dan misi konservasi dan kecintaan lingkungan. Hal ini dapat terjadi karena keuntungan finansial yang didapat dari biaya perjalanan wisata digunakan juga untuk kebutuhan konservasi alam serta perbaikan kesejahteraan penduduk lokal. Di sisi lain, konsep ekowisata juga diarahkan untuk mempertahankan kebudayaan lokal serta tidak melanggar Hak Asasi Manusia (HAM) dan pergerakan demografi.

Pergeseran konsep kepariwisataan dunia ke model ekowisata, disebabkan karena kejenuhan wisatawan untuk mengunjungi obyek wisata buatan. Oleh karena itu peluang 
ini selayaknya dapat dimanfaatkan secara optimal untuk menarik wisatawan mengunjungi objek berbasis alam dan budaya penduduk lokal.

Ekowisata di Wonosalam dengan produk utama jelajah hutan, sungai, mata air dan bird watching, berpeluang untuk dikolaborasikan dengan agrowisata. Mengingat potensi lokal yang dimiliki Wonosalam adalah beraneka tanaman buah dan non-buah, di antaranya durian, kopi, teh, coklat, cengkeh.

Agrowisata terdiri dari 5 obyek daya tarik wisata (ODTW): kebun raya, perkebunan, tanaman pangan dan hortikultura, perikanan dan peternakan. Berbagai kekayaan wisata agro baik yang dimiliki pemerintah, Badan Usaha Milik Negara (PTPN X, XI, dan XII) dan secara pribadi tersebar di hampir 38 kabupaten/kota di Jawa Timur. Atraksi wisata agro perkebunan yang ditampilkan di antaranya perkebunan kopi (Robusta dan Arabica), Caco, Tebu/Gula, Teh, Karet, Apel, Durian, Jeruk.

Wonosalam memiliki potensi ekowisata yang besar. Melalui pengabdian masyarakat dengan skema Program Pengembangan Desa Mitra dapat dikolaborasikan dengan agrowisata dengan fasilitasi pemerintah serta stakeholder terkait. Namun selama ini hal itu belum dilakukan, sehingga diversifikasi produk ekowisata dan agrowisata di Wonosalam belum menyatu menjadi suatu kekuatan obyek wisata yang besar yang dikenal oleh wisatawan.

Upaya untuk memperkuat destinasi ekowisata dan agrowisata berpeluang besar untuk menarik kunjungan wisatawan. Di mana, perubahan tren pariwisata global yang sedang terjadi dari mass tourism menjadi quality tourism, menempatkan ekowisata dan agrowisata sebagai destinasi wisata yang menjadi rujukan pasar wisatawan dunia.

\section{Permasalahan Mitra}

Lingkungan Dusun Mendiro, Desa Panglungan, Kecamatan Wonosalam, Kabupaten Jombang, yang menjadi fokus kegiatan pengabdian masyarakat, mengalami sejumlah masalah. Yakni, pencurian burung satwa langka, penebangan pohon liar, pencemaran sungai, serta alih kepemilikan lahan ke orang luar daerah. Padahal, keberadaan mereka yang berdekatan dengan hutan lindung sangat penting perannya untuk menjaga kelestarian hutan, mata air dan sungai.

\section{Tujuan PKM}

Permasalahan mitra di atas memerlukan soluasi yang perlu dipecahkan bersama. Pada Program Pengembangan Desa Mitra (PPDM) ini, tim pengabdian masyarakat dari jurusan Hotel \& Tourism Business, Universitas Ciputra Surabaya akan memberikan solusi dengan bekerjasama warga menciptakan desa ekowisata untuk menyelamatkan hutan, mata air dan sungai.

Tujuan menciptakan desa ekowisata tersebut dilaksanakan agar segenap komponen masyarakat, mulai dari kaum muda, sesepuh, kelompok ibu dan kaum perempuan, tokoh daerah, serta pemerintah di tingkat desa, memiliki komitmen yang sama untuk memajukan desa melalui ekowisata. Melalui berbagai kegiatan pelatihan, penyuluhan dan pendampingan, telah terjadi peningkatan pengetahuan dan keterampilan dalam hal ekowisata dan manajemen pariwisata berbasis masyarakat, pertumbuhan kualitas hidup masyarakat, serta bertambahnya pendapatan dari kunjungan wisatawan.

Dengan adanya PPDM yang bertujuan menciptakan desa ekowisata berbasis masyarakat, maka akan meningkatkan kesejahteraan masyarakat, khususnya di Dusun Mendiro, Desa Panglungan, Kabupaten Jombang. Nurhidayati (2007) mendefinisikan CBT: (1) bentuk pariwisata yang memberikan kesempatan kepada masyarakat lokal untuk 
mengontrol dan terlibat dalam manajemen dan pembangunan pariwisata, (2) masyarakat yang tidak terlibat langsung dalam usaha-usaha pariwisata juga mendapat keuntungan, dan (3) menuntut pemberdayaan secara politis dan demokratisasi dan distribusi keuntungan kepada komunitas yang kurang beruntung. Jadi, intinya, CBT merupakan perwujudan pemerluasan dampak sektor pariwisata pada pembangunan perekonomian lokal (local economic development) masyarakat di sekitar kawasan wisata. Upaya yang ditempuh melalui peluang yang diberikan kepada masyarakat untuk mendapatkan pekerjaan dan kesempatan berwirausaha di sektor pariwisata secara lebih luas.

Pembangunan pariwisata berbasis masyarakat juga dapat didefinisikan sebagai sebuah aktivitas masyarakat lokal untuk mempromosikan berbagai nilai dan menciptakan suatu masyarakat yang diisi dengan energi, dengan memanfaatkan alam, budaya, sejarah, industri, orang-orang yang mempunyai bakat, dan sumber-sumber daya lainnya secara penuh. Pembangunan pariwisata berbasis masyarakat menginginkan seluruh komponen masyarakat untuk berfikir, berdiskusi, dan mengambil tindakantindakan nyata (Natori, dalam Madiun, 2010). Melalui pembangunan pariwisata berbasis masyarakat, juga akan tercapai cita-cita kepariwisataan yang diamanatkan dalam Undang-undang Pariwisata Nomer 10 tahun 2009.

\section{METODE PELAKSANAAN}

Berdasarkan analisis masalah di atas, pelaksanaan kegiatan pengabdian masyarakat skim "Program Pengembangan Desa Mitra" dilakukan sebagai berikut:

Pelatihan penguatan produk wisata melalui: pembenahan infrastruktur jalan untuk tracking wisata hutan, sungai dan mata air, pembangunan warung desa dan toilet, renovasi homestay, serta signage yang berfungsi sebagai penunjuk arah di dalam area ekowisata. Di bidang sumber daya manusia, dilakukan pelatihan bahasa Inggris, pelatihan pengemasan paket wisata, tour guiding, digital marketing, penyajian makanan dan minuman khas desa Penyuluhan dan workshop sadar wisata dan service excellent untuk menumbuhkan pengetahuan dan keterampilan dalam mengelola desa ekowisata berbasis masyarakat.

Tim pengabdi telah memfasilitasi pembentukan kelembagaan pengelola desa wisata dalam Kelompok Sadar Wisata (Pokdarwis) yang dilegalkan melalui Surat Keputusan (SK) Kepala Desa. Selain Pokdarwis, tim pelaksana juga menyiapkan tim khusus Public Relation dan Marketing yang berasal dari warga Wonosalam yang memiliki ketertarikan dalam marketing. Mereka dilatih secara khusus untuk mengelola website yang nantinya akan digunakan untuk online reservation, serta social media untuk mempromosikan Wonosalam di Instagram, Facebook, Twitter dan Youtube.

Kegiatan pengabdian ini dilaporkan dengan mengadopsi pendekatan penelitian kualitatif deskriptif, merupakan metode yang memfokuskan perhatiannya pada prinsipprinsip umum yang mendasari satuan-satuan yang berkaitan dengan tema penelitian. Teknik pengumpulan data primer melalui wawancara, focus group discussion, dan observasi. Data sekunder diperoleh melalui studi literatur terkait.

Sumber data dalam penelitian ini diambil dengan prosedur purposive sampling, di mana melalui sampling yang terpenting adalah bagaimana menentukan narasumber kunci atau situasi sosial tertentu yang sarat informasi sesuai dengan fokus penelitian. Narasumber kunci adalah pihak yang memiliki posisi sosial dalam pengaturan riset karena memiliki pengetahuan spesialis mengenai orang lain, proses, atau kejadian yang lebih ekstensif, detail atau lebih utama dari orang biasa, dan merupakan sumber informasi 
berharga bagi seorang peneliti, paling tidak pada tahap awal suatu proyek (Myers, 2009: 144).

Analisis data adalah proses yang mengatur urutan data, mengorganisasikannya ke dalam suatu pola, kategori, dan uraian dasar. Analisis data sebagai suatu proses yang merinci usaha formal untuk menemukan tema dan merumuskan ide sebagai yang disarankan oleh data, dan sebagai usaha untuk memberikan bantuan pada tema dan ide tersebut (Aries, 2010: 56). Analisis data yang terkumpul dalam penelitian ini menggunakan pendekatan analisis deskriptif yang merupakan pendekatan spesifik terhadap analisis data kualitatif.

\section{HASIL DAN PEMBAHASAN}

\section{Pelatihan Pengemasan Produk Ekowisata}

Tim pengabdi telah membantu merumuskan produk unggulan ekowisata Wonosalam berdasarkan sumber daya yang dimiliki. Yakni, Jelajah Hutan, Jelajah Sungai, Jelajah Mata Air, dan Jelajah Desa. Empat produk unggulan ini mencakup, tracking hutan, bird watching dan menikmati pemandangan di area yang ditentukan sebagai good view point. Di ranah ini, bentuk pengabdian difokuskan pada pembuatan flow / alur kunjungan, yang kemudian diperkuat dengan pemasangan signage, perapian jalan di hutan untuk meningkatkan keamanan dan kenyamanan, dan pengadaan peralatan telekomunikasi handy talky serta megaphone yang dapat membantu warga dalam memberikan pelayanan kepada wisatawan ketika berkunjung ke hutan Mendiro, Wonosalam.

Ketua Kelompok Pelindung dan Pelestari Hutan (KEPUH) Dusun Mendiro, Desa Panglungan, Kecamatan Wonosalam, Kabupaten Jombang, Wagisan, menyatakan, "delapan angota KEPUH yang selama ini bertugas menjaga hutan lindung di Dusun Mendiro, terbantu dan terfasilitasi dengan baik dengan adanya pendampingan dari Program Universitas Ciputra." Pendampingan ditujukan ke anggota KEPUH yang dipersiapkan sebagai Tour Guide sekaligus Tour Leader untuk 4 (empat) produk ekowisata, yakni wisata hutan, mata air, sungai dan wisata desa.

Oleh karena potensi wisata hutan sangat luas, maka program pengemasan produk ekowisata difokuskan pada pembuatan alur kunjungan wisata, pemasangan signage, serta perbaikan di area tertentu untuk menambah keamanan dan kenyamanan dalam berwisata. Tumari, anggota KEPUH, menyatakan, "ada dua rute dalam wisata hutan, pertama, rute pendek, hasil pengemasan alur kunjungan wisata hutan Mendiro mulai dari Dusun Mendiro, masuk ke area Tanah Kas Desa, menuju mata air Kendil Wesi, diakhiri di area Good View". Tumari menjelaskan, "rute kedua, rute panjang, ditambah dengan eksplorasi ke Sungai Boro".

\section{Perbaikan Infrastruktur}

Dalam hal infrastruktur, tim pengabdi memfokuskan pada pembuatan toilet, warung desa dan renovasi homestay. Kegiatan pengabdian dengan memperbaiki tiga infrastruktur tersebut menggunakan tenaga lokal. Adapun ketiga bentuk infrastruktur tersebut dibuat berdasarkan analisa kebutuhan yang urgen di lapangan.

Perbaikan homestay ditujukan ke lima rumah warga yang bersedia dan berkomitmen untuk dijadikan homestay. Anti, salah satu pemilik homestay, menyatakan, "dengan adanya program homestay dari Universitas Ciputra, menambah kesiapan warga Dusun Mendiro 
untuk menjadi desa ekowisata." Adapun perbaikan homestay terdiri dari renovasi satu kamar tidur dan kamar mandi agar layak pakai untuk tamu.

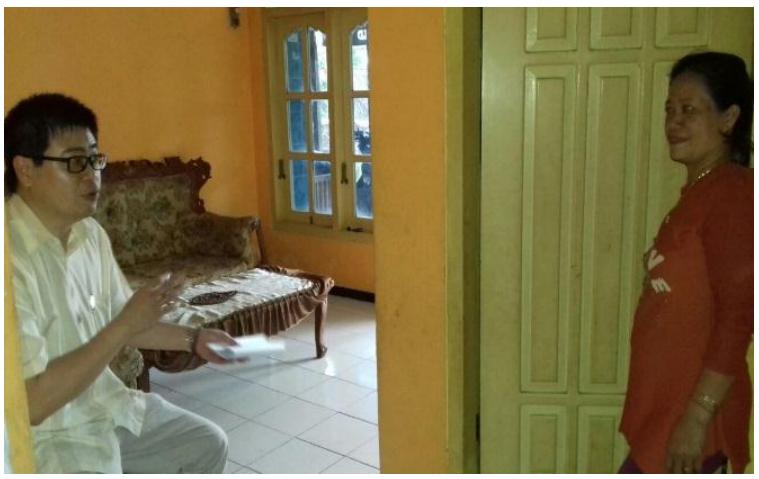

Gambar 1. Renovasi Homestay

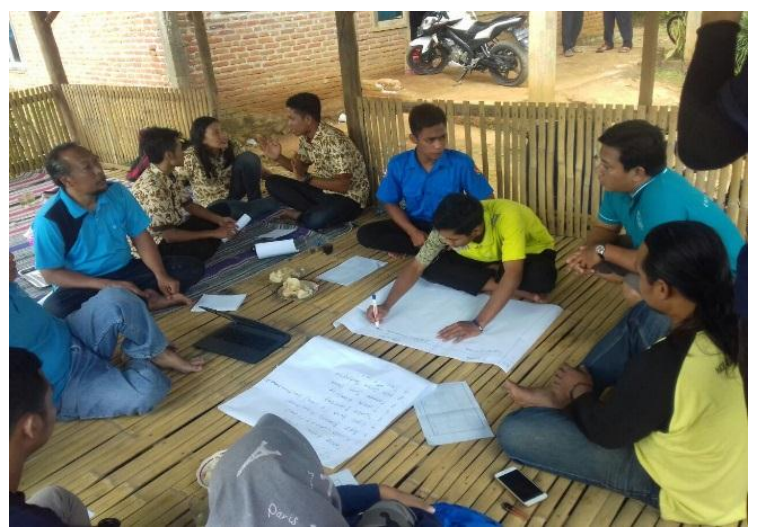

Gambar 2. Koordinasi Pembuatan Warung Desa

\section{Pelatihan Bahasa Inggris}

Dalam hal kemampuan berbahasa Inggris, strategi yang dilakukan oleh tim pengabdi adalah melakukan beberapa pertemuan dengan anggota Kepuh dan kaum muda yang bersekolah di MI Faser di Wonosalam untuk diberi pelatihan khusus bahasa Inggris. Karena mereka yang akan menjadi 'ujung tombak' dalam menerima dan melayani tamu wisatawan, yang selama tim pengabdi menjalankan program telah dikunjungi wisatawan mancanegara. Memang, pelatihan berbahasa Inggris tidak dapat dalam jangka pendek, karena itu tim pengabdi berupaya untuk menambah jam pelatihan bahasa Inggris.

Pelatihan bahasa Inggris ditujukan kepada semua anggota KEPUH, yang notabene dari segi usia tergolong senior, tetapi sangat memahami hutan lindung, dari segi rute maupun jenis tanaman pohon. Sukarianto, salah satu anggota KEPUH yang ikut pelatihan bahasa Inggris menyatakan, "sulit sekali belajar bahasa Inggris untuk dipraktekkan di wisata hutan, tetapi kalau sudah terbiasa akan semakin mudah". Pelatihan bahasa Inggris secara praktis dilakukan dengan cara mengikuti kebiasan atau standard KEPUH ketika membawa tamu berwisata ke hutan. Karena itu, materi bahasa Inggris yang terdokumentasi dalam bentuk rekaman MP3, menyajikan bahasa Inggris praktis, mulai dari penyambutan, pengenalan jenis-jenis pohon, daya tarik dan keunikan hutan lindung, serta kearifan lokal yang dijunjung warga desa. 


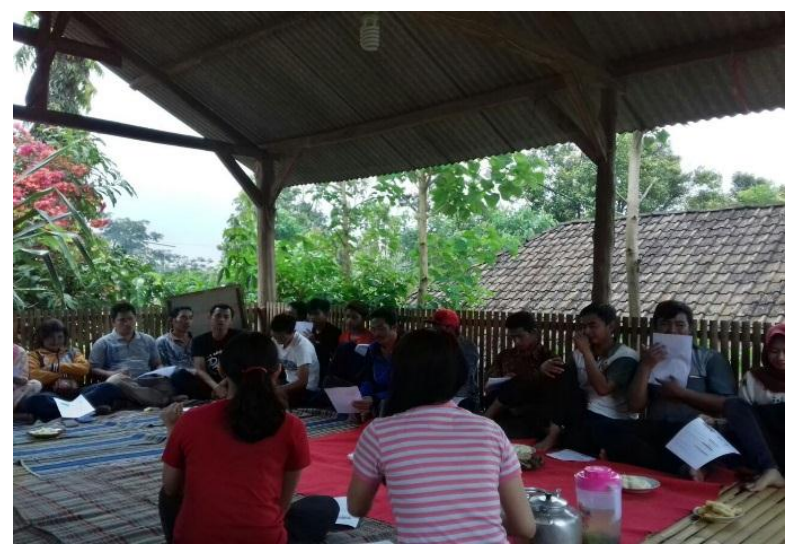

Gambar 3. Suasana Pelatihan Bahasa Inggris

\section{SIMPULAN}

Pengabdian dengan skim PPDM dapat disimpulkan bahwa kegiatan pengabdian kepada masyarakat ini dapat meningkatkan keterampilan dan pengetahuan warga Wonosalam, khususnya di Desa Panglungan, akan pengelolaan desa ekowisata berbasis masyarakat. Diharapkan, keberlanjutan program di tahun berikutnya dapat semakin memacu dan mempercepat kemajuan desa ekowisata di Wonosalam.

\section{REFERENSI}

Aries, E. F. (2010). Design action research. Malang: Aditya Media Publishing.

Damanik, J., \& Weber, H. F. (2006). Perencanaan ekowisata: Dari teori ke aplikasi. Yogyakarta: Puspar UGM dan Andi.

Fandeli, C. (2000). Pengertian dan konsep dasar ekowisata. Yogyakarta: Fakultas Kehutanan UGM.

Madiun, I. N. (2010). Nusa Dua: Model pengembangan kawasan pariwisata modern. Denpasar: Udayana University Press.

Myers, M. D. (2009). Qualitative research in business \& management. London: SAGE Publication.

Nurhidayati, S. E. (2007). Community based tourism (CBT) sebagai pendekatan pembangunan pariwisata berkelanjutan. Jurnal Masyarakat, Kebudayaan, dan Politik, 20(3), 191-202.

Satria, D. (2009). Strategi pengembangan ekowisata berbasis ekonomi lokal dalam rangka program pengentasan kemiskinan di wilayah Kabupaten Malang. Journal of Indonesian Applied Economics, 3(1), 37-47.

Undang-undang Nomor 10 Tahun 2009 tentang Kepariwisataan. 